\title{
Mapping extinction debt highlights conservation opportunities for birds and mammals in the South American Chaco
}

\author{
Asunción Semper-Pascual ${ }^{1}$ (D) | Leandro Macchi ${ }^{1,2}$ | Francesco Maria Sabatini ${ }^{1}$ | \\ Julieta Decarre $^{3}$ | Matthias Baumann ${ }^{1}$ | Pedro G. Blendinger ${ }^{2}$ | Bibiana Gómez-Valencia ${ }^{4}$ | \\ Matías E. Mastrangelo ${ }^{5}$ | Tobias Kuemmerle ${ }^{1,6}$
}

${ }^{1}$ Geography Department, Humboldt-Universität zu Berlin, Berlin, Germany; ${ }^{2}$ Instituto Ecología Regional (IER), CONICET - Universidad Nacional de Tucumán, Tucumán, Argentina; ${ }^{3}$ Centro de Investigación en Recursos Naturales (CIRN-IRB), Instituto Nacional de Tecnología Agropecuaria (INTA), Córdoba, Argentina; ${ }^{4} G$ rupo de Estudios de Sistemas Ecológicos en Ambientes Agrícolas, Facultad de Ciencias Exactas y Naturales, Universidad de Buenos Aires, Buenos Aires, Argentina; ${ }^{5}$ CONICET - Grupo de Estudios de Agroecosistemas y Paisajes Rurales (GEAP), Universidad Nacional de Mar del Plata, Mar del Plata, Buenos Aires, Argentina and ${ }^{6}$ Integrative Research Institute on Transformations of Human-Environment Systems (IRI THESys), Berlin, Germany

\section{Correspondence}

Asunción Semper-Pascual

Email: asuncion.semper.pascual@

geo.hu-berlin.de

\section{Funding information}

Deutsche Forschungsgemeinschaft, Grant/ Award Number: Project KU 2458/5-1; German Ministry of Education and Research, Grant/Award Number: 031B0034A

Handling Editor: Cristina Banks-Leite

\section{Abstract}

1. Habitat loss is the primary cause of local extinctions. Yet, there is considerable uncertainty regarding how fast species respond to habitat loss, and how time-delayed responses vary in space.

2. We focused on the Argentine Dry Chaco (c. 32 million ha), a global deforestation hotspot, and tested for time-delayed response of bird and mammal communities to landscape transformation. We quantified the magnitude of extinction debt by modelling contemporary species richness as a function of either contemporary or past (2000 and 1985) landscape patterns. We then used these models to map communities' extinction debt.

3. We found strong evidence for an extinction debt: landscape structure from 2000 explained contemporary species richness of birds and mammals better than contemporary and 1985 landscapes. This suggests time-delayed responses between 10 and 25 years. Extinction debt was especially strong for forest specialists.

4. Projecting our models across the Chaco highlighted areas where future local extinctions due to unpaid extinction debt are likely. Areas recently converted to agriculture had highest extinction debt, regardless of the post-conversion land use. Few local extinctions were predicted in areas with remaining larger forest patches.

5. Synthesis and applications. The evidence for an unpaid extinction debt in the Argentine Dry Chaco provides a substantial window of opportunity for averting local biodiversity losses. However, this window may close rapidly if conservation activities such as habitat restoration are not implemented swiftly. Our extinction debt maps highlight areas where such conservation activities should be implemented.

KEYWORDS

agricultural expansion, biodiversity loss, deforestation, extinction debt, Gran Chaco, habitat loss, landscape transformation, restoration, time-delayed responses, tropical dry forest 


\section{1 | INTRODUCTION}

Populations of numerous species have recently undergone rapid decline, leading to local extinctions (Ceballos et al., 2015; Pimm et al., 2014). The primary cause of these declines has been land-use change, mainly through the loss, degradation and fragmentation of habitat (Ehrlich \& Pringle, 2008; Foley et al., 2005). Therefore, understanding how habitat transformation affects local extinctions is crucial to understand ongoing community changes and prevent future biodiversity loss.

Although local extinction can occur immediately, time delays between habitat transformations and biodiversity declines occur frequently (Essl et al., 2015; Kuussaari et al., 2009). Tilman, May, Lehman, and Nowak (1994) introduced the term "extinction debt" to describe such time-delayed responses, defined as the number or proportion of extant species predicted to go extinct due to past landscape transformation. Extinction debt can be detected by comparing the relationship between landscape structure and current species richness. Evidence for an extinction debt exists when past landscape structure explains current richness better than current landscape structure. A critical assumption behind this approach is that species richness was in equilibrium before landscape transformation, and species will slowly disappear until the community reaches a new equilibrium with the environment.

The probability and duration of time-delayed responses may vary due to different factors (Kuussaari et al., 2009; Ovaskainen \& Hanski, 2002). First, the magnitude of habitat perturbation may influence the pace with which species respond to landscape transformation (Lira, Ewers, Banks-Leite, Pardini, \& Metzger, 2012; e.g. species may survive longer if forests are only thinned compared to clear cut). Second, the extent of habitat transformation may influence the number of predicted extinctions (May \& Lawton, 1995; e.g. if habitat loss occurs only locally, species may move to remaining patches and therefore persist longer). Finally, species' traits may influence time-delayed responses (Metzger et al., 2009; e.g. long-lived species and habitat specialists are more likely to show delayed responses compared to short-lived species and generalists). Given this variability in the probability and duration of time-delayed responses, it is essential to understand the processes underlying such delays. In addition, understanding timedelayed responses is crucial from a conservation perspective, as documenting the number of species found in situ without considering extinction debt might lead to an underestimation of threat level (Hanski \& Ovaskainen, 2002). Most importantly, identifying extinction debt may provide a window of opportunity for conservation to prevent extinctions (e.g. by restoring habitat for species affected by extinction debt).

Even though time-delayed responses to habitat transformation have received considerable attention, many gaps in our understanding of extinction debt remain. For example, whereas extinction debt should be more likely to occur in landscapes undergoing recent and widespread habitat transformations (Hanski \& Ovaskainen, 2002), such as in tropical deforestation frontiers, most studies so far have focused on regions where habitat transformation occurred slowly and gradually (Helm, Hanski, \& Pärtel, 2006; Herrault et al., 2016; Krauss et al., 2010; Lindborg \& Eriksson, 2004). Most extinction debt studies so far have also focused on relatively small areas (Chen \& Peng, 2017), and therefore, extinction debt at landscape-to-regional scales, where most conservation planning takes place, is weakly understood. Additionally, there has been a strong focus on plants (Helm et al., 2006; Lindborg \& Eriksson, 2004) and birds (Brooks, Pimm, \& Oyugi, 1999; Lira et al., 2012; Metzger et al., 2009), while the importance of extinction debt for other threatened taxa (IUCN, 2016), especially mammals, remains largely unknown.

While identifying extinction debt provides an imperative to act, many extinction debt studies are non-spatial and thus leave the question of where to act unanswered. Very few studies have attempted to map extinction debt (Chen \& Peng, 2017; Cowlishaw, 1999; Soga \& Koike, 2013; Wearn, Reuman, \& Ewers, 2012), mostly relying on species-area relationships which are prone to overestimating extinction rates (He \& Hubbell, 2011). Here, we present a new approach for mapping extinction debt based on mapping species richness in the current landscape and in a new, future equilibrium after relaxation. Our overall goal was to investigate time-delayed responses in bird and mammal communities caused by landscape transformation in the Argentine Dry Chaco, a highly dynamic deforestation frontier. To test for and map extinction debt, we examined the influence of landscape structure on contemporary species richness (2009-2015) based on landscape structure from three time periods (1985, 2000 and contemporary). Specifically, we explored the following research questions:

1. What are the relationships between contemporary richness of birds and mammals, and historical and contemporary landscape structure?

2. Are there differences in time-delayed responses to landscape transformation between birds and mammals, and between forestdependent species and the entire community?

3. Which areas of the Argentine Dry Chaco are likely to experience local extinctions due to an unpaid extinction debt, and how does the magnitude of this extinction debt vary across space?

\section{MATERIALS AND METHODS}

\section{1 | Study area}

Our study area (Figure 1) is located in the Gran Chaco region, South America's largest tropical dry forest, stretching into Argentina, Paraguay, Bolivia and Brazil (Bucher \& Huszar, 1999). Since the 1990s, and especially after 2000 , the region experienced one of the highest deforestation rates world-wide, mainly due to the expansion of soybean production and industrial cattle ranching (Baumann et al., 2017; Gasparri \& Baldi, 2013; Grau, Gasparri, \& Aide, 2005). The Chaco is also considered a biodiversity hotspot, harbouring more than 400 birds, 150 mammals, 120 reptiles and 100 amphibian species (The Nature Conservancy (TNC), Fundación Vida Silvestre Argentina (FVSA), Fundación para el Desarrollo Sustentable del Chaco (DeSdel Chaco) \& Wildlife Conservation Society Bolivia (WCS), 2005). Given 
FIGURE 1 Location of the study area in (a) South America and (b) Northern Argentina, including bird and mammal sampling sites

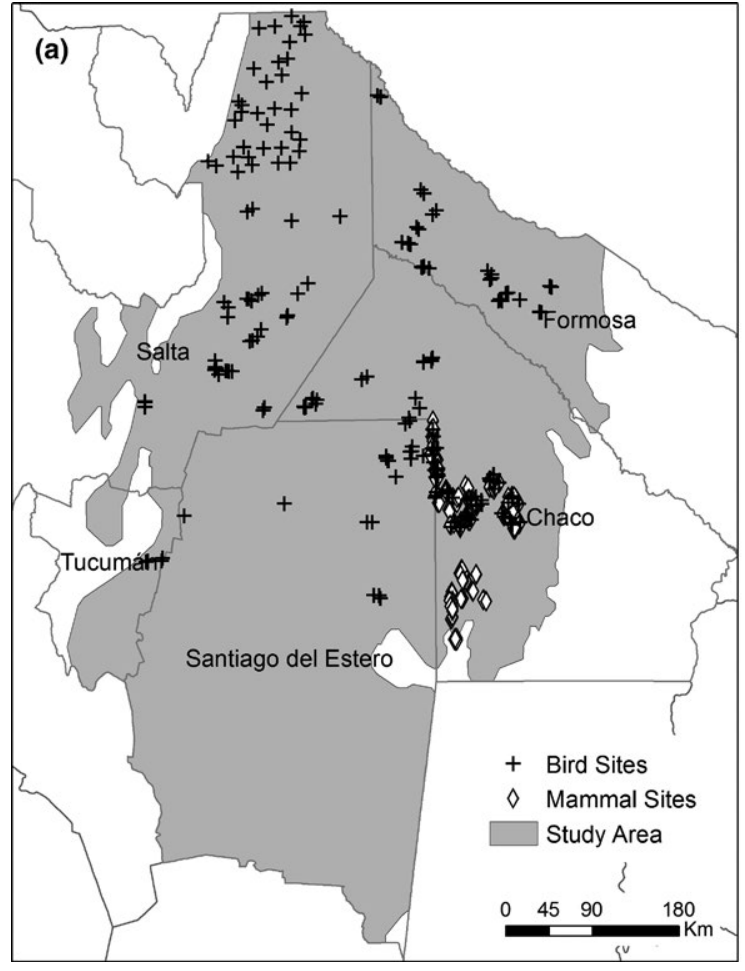

the high biodiversity, the high anthropogenic pressure and the limited extent of protected areas (9\%; Nori et al., 2016), the Chaco is in urgent need of conservation action (Kuemmerle et al., 2017).

The Chaco can be subdivided along a precipitation gradient, with the Wet Chaco in the East $(900-1,200 \mathrm{~mm})$, the Dry Chaco in the West $(450-700 \mathrm{~mm})$ and a transition area in between $(700-900 \mathrm{~mm}$; Cabrera \& Willink, 1973). We focused on the northern Argentine Dry Chaco (covering c. 32 million ha, Figure 1), an area characterized by semi-deciduous xerophytic forests, with interspersed shrublands, savannas and grasslands (Bucher \& Huszar, 1999; Cabrera \& Willink, 1973). Much of the area has recently been converted to pastures and croplands (Baumann et al., 2017), and most remaining natural forests and grasslands are grazed by livestock (Bucher \& Huszar, 1999).

\section{2 | Biodiversity data}

We used extensive field data available from previous studies on birds (Decarre, 2015; Macchi, Grau, Zelaya, \& Marinaro, 2013; Mastrangelo \& Gavin, 2012) and mammals (Decarre, 2015; Gómez-Valencia, 2017). For both taxa, we used (1) total species richness and (2) forestdependent species richness as our response variables.

Birds were surveyed at 227 sites between 2009 and 2013. Each site was sampled using point counts, where all bird individuals were identified to species level. All species recorded were classified into forest-dependent (hereafter: forest species) and species preferring non-forest environments (hereafter: non-forest species) according to our own field experience (Decarre, 2015; Macchi et al., 2013), experts' knowledge (Torres, Gasparri, Blendinger, \& Grau, 2014) and existing literature (del Hoyo, 2015; Ridgely \& Tudor, 1994; Short, 1975; Table S1). We excluded migratory species to minimize seasonal effects.
In total, we included 212 bird species in our analyses of which 74 were forest species (Table S1). Because the number of point counts per site varied depending on the study (4, 6 and 9 point counts), we calculated rarefied richness for the entire community and for the forest species using sample-based rarefaction curves to correct for uneven sampling efforts. We rarefied all sites to the smallest sampling effort (i.e. 4 point counts) using the vegan package in $\mathrm{R}$ (Oksanen et al., 2016). A sample coverage curve (Figure S1) suggests that rarefying to 4 point counts does only marginally underestimate species richness as opposed to rarefying and extrapolating to 6 or 9 point counts, a conclusion also supported by the relationship between original richness and estimated rarefied richness (Figure S2).

Medium and large-bodied mammals were surveyed at 226 sites from 2012 to 2015, using camera traps. Sites were chosen randomly, while avoiding trails. Mammals were classified into forest and nonforest species following expert recommendations (Decarre, 2015; Gómez-Valencia, 2017) and literature (Canevari \& Vaccaro, 2007). We documented a total of 26 mammal species in the study area, with 11 forest species (Table S2). Cameras were active between 9 and 153 camera-trap nights per site $(M=43)$, with 9,719 camera-trap nights in total. To correct for differences in camera-trap nights among sites without having to discard substantial amounts of data, we generated rarefaction curves following Colwell et al. (2012), using the R package iNEXT (Hsieh, Ma, \& Chao, 2016). Instead of rarefying all the sites to the lowest sampling effort, this method allows to rarefy sites with a high number of camera-trap nights and extrapolate sites with a low number of camera-trap nights to a common number (i.e. in our case 39 and 40 camera-trap nights for the entire community and for the forest species respectively, which represents the mean number of cameratrap nights, after excluding the outliers). Since iNEXT cannot handle 
sites with identical capture records, we excluded duplicate sites yielding a final sample size of 223 sites for the entire community and 225 for forest species.

Further details on the field methods are provided in Appendix S1, including a comparison of original and the estimated rarefied richness (Figure S2).

\section{3 | Landscape variables}

We selected two landscape predictors as proxies for habitat availability (percentage of forest, percentage of core forest) and three landscape predictors as proxies for habitat connectivity (percentage of edge between forest and non-forest patches, percentage of connectivity, aggregation index) around each sampling site (Table 1 and Table S3). We estimated these five landscape predictors for each time period, i.e. 1985, 2000 and contemporary (Table 1), based on different Landsat-based land-cover data. We used the Global Forest Change map from Hansen et al. (2013) to derive contemporary (from 2009 to 2013) and past (2000) forest extent and configuration, and a landcover map from Baumann et al. (2017) to assess past (1985) landscape configuration (Appendix S2). Both maps have a high accuracy $(99 \%$ and $88 \%$, respectively) and comparing the estimated forest loss areas for the post-2000 period suggests that both maps are well-aligned. Since bird data were collected in different years (from 2009 to 2013), we extracted contemporary landscape data for the specific year in which a site was sampled, thus accounting for land-use changes during the sampling period (e.g. sites sampled in 2009 were related to forest cover from 2009). For the mammal dataset (sampled between 2012 and 2015), we used forest maps from 2013 since more recent land-cover maps were not available.

We derived landscape data in a circular buffer around each sampling site. For birds, we used a 3-km radius in accordance with other studies testing the influence of landscape configuration on bird richness and abundance (Deconchat, Brockerhoff, \& Barbaro, 2009; Mastrangelo \& Gavin, 2014; Mitchell, Lancia, \& Gerwin, 2001). For mammals, we used a $2-\mathrm{km}$ radius, which represents the average home range sizes of medium and large mammals found in the area (Beisiegel \& Mantovani, 2006; Canevari \& Vaccaro, 2007; IUCN, 2016; Kasper, Soares, \& Freitas, 2012; Schai-Braun \& Hackländer, 2014). We used Morphological Spatial Pattern Analysis (Vogt et al., 2007), available in the GUIDOS software, and SDMTools package (VanDerWal, Falconi, Januchowski, Shoo, \& Storlie, 2014) in R to derive landscape metrics. To investigate whether extinction debt is caused by landscape transformation or other factors, we also included a number of control variables related to human disturbance, climate and water availability that could affect birds and mammals in the Dry Chaco (Table 1 and Table S3).

\section{4 | Testing for extinction debt}

Investigating extinction debt relies on the assumption that communities were in equilibrium with the landscape before major habitat

TABLE 1 Predictors for explaining bird and mammal richness in the Chaco

\begin{tabular}{|c|c|c|}
\hline Predictor by group & Name & Description \\
\hline Extent of forest & Forest & Percentage of forest in the buffer \\
\hline Extent of core forest & Core & Percentage of interior area of forest excluding forest perimeter in the buffer \\
\hline $\begin{array}{l}\text { Extent of edge between forested } \\
\text { and non-forested patches }\end{array}$ & Edge & Percentage of outside perimeter pixels in the buffer \\
\hline Aggregation & Aggre & $\begin{array}{l}\text { Number of like adjacencies between forest patches, divided by the maximum possible } \\
\text { number of like adjacencies between forest patches, multiplied by } 100 \text { (to convert to a } \\
\text { percentage; McGarigal, 2014) }\end{array}$ \\
\hline \multicolumn{3}{|l|}{ Human disturbance } \\
\hline Distance to big settlements & DistTown & Euclidean distance $(\mathrm{km})$ to the closest settlement with more than 900 inhabitants \\
\hline \multicolumn{3}{|l|}{ Climate } \\
\hline Long-term temperature & Temp & $\begin{array}{l}\text { Mean temperature }\left({ }^{\circ} \mathrm{C}\right) \text { for the } 10 \text { years before each period of time }(1975-1985 \text { for } \\
1985 ; 1990-2000 \text { for } 2000 \text {; and } 2000-2010 \text { for the contemporary period) }\end{array}$ \\
\hline Long-term precipitation & Prec & Mean precipitation $(\mathrm{mm})$ for the 10 years before each period of time \\
\hline Aridity & Aridity & Aridity index for the year when the species were sampled \\
\hline \multicolumn{3}{|l|}{ Water availability } \\
\hline Density of rivers & DensRiver & Density of rivers in the buffer $\left(\mathrm{km} / \mathrm{km}^{2}\right)$ \\
\hline Distance to water bodies & DistWater & Euclidean distance $(\mathrm{km})$ to the closest permanent water body \\
\hline
\end{tabular}


perturbations occurred (Kuussaari et al., 2009). Although degradation in the Dry Chaco started long ago, major changes in the landscape have only occurred since the mid-1990s (Baumann et al., 2017; Caldas, Goodin, Sherwood, Campos Krauer, \& Wisely, 2015). We therefore assumed an equilibrium state at the beginning of our study period. We carried out two analyses: first, we tested for the existence of extinction debt separately for birds and mammals. Second, we mapped the magnitude of the potential extinction debt per group.

To test for the existence of an extinction debt, we first investigated the relationships between contemporary species richness and (1) contemporary landscape predictors, (2) year-2000 predictors, and (3) year-1985 predictors (i.e. each model only contained landscape predictors from one time period). For each time period, we considered four response variables: the contemporary rarefied richness of (1) all birds, (2) forest birds, (3) all mammals and (4) forest mammals. For each time period and response variable, we parametrized models with and without landscape variables to investigate whether extinction debt was caused by landscape transformation or other factors (e.g. climate change; Tables S4 and S5). When two predictors were collinear (Spearman correlation coefficient $>0.6$ ), we retained the variable with the most ecologically meaningful relationship with species richness (Tables S4 and S5). We standardized all predictors $(M=0$, $S D=1$ ) to assess their relative importance (Schielzeth, 2010). Since bird data were from different sources, we controlled for varying sampling designs using linear mixed models that included the categorical variable sampling design as a random intercept, using the $\mathrm{R}$ package nlme (Pinheiro, Bates, DebRoy, \& Sarkar, 2016). For the mammal data, we used simple linear models, as the study design did not vary between the two datasets.

When analysing forest species, for both birds and mammals, we used a two-step hurdle modelling approach to account for the zeroinflation caused by many sites without forest species. We first modelled the probability of forest species occurrence (presence-absence data), and then analysed the variation in the number of forest species for sites with forest species (presence-only data). We fitted our data using generalized linear models (generalized linear mixed models for the forest birds) with a binomial distribution for the presence-absence model, and a gamma distribution for the presence-only model using the R package Ime4 (Bates, Maechler, Bolker, \& Walker, 2015).

Finally, we checked for the existence of spatial autocorrelation by computing the semi-variogram of the residuals. We used the Akaike's information criterion (AIC; Burnham \& Anderson, 2002) to determine which model explained species richness best, ranked models using $\triangle \mathrm{AIC}$, considering models with a $\Delta \mathrm{AIC}<2$ to equally be supported. We also calculated Akaike weights to quantify the probability of each candidate model of being the best model (Wagenmakers \& Farrell, 2004). For the hurdle models, we calculated AIC by adding the AICs of the two individual models (Zuur \& leno, 2016).

\section{5 | Mapping extinction debt}

To map extinction debt for the entire community, we used our models to predict (1) contemporary total species richness and (2) total species richness after extinction debt has been paid (Figure 2). This assumes that communities are in equilibrium before large-scale habitat transformation (before 1990 in our case). Following land-use change, species are lost either immediately or gradually, due to extinction debt, until a new, future equilibrium is reached. The difference between the old and new equilibrium represents the total number of species going extinct as a consequence of land-use change, whereas the difference between contemporary richness and the future equilibrium represents the extinction debt (Figure 2).

To predict contemporary richness patterns, we used the model that explained contemporary biodiversity patterns as observed via bird counts and mammal camera trapping best (i.e. the model with lowest AIC; hereafter: best-fitting model, Figure 3). In the presence of an extinction debt, this model should contain historical landscape predictors. We then project the same best-fitting model to contemporary landscape patterns (i.e. using the same set of predictor variables and regression coefficients, but replacing historical landscape predictors with contemporary predictors). This predicts the total number of species that can persist in the new landscape, that is species richness from the past equilibrium minus those species lost immediately (and therefore not in our dataset) and those that will be lost due to extinction

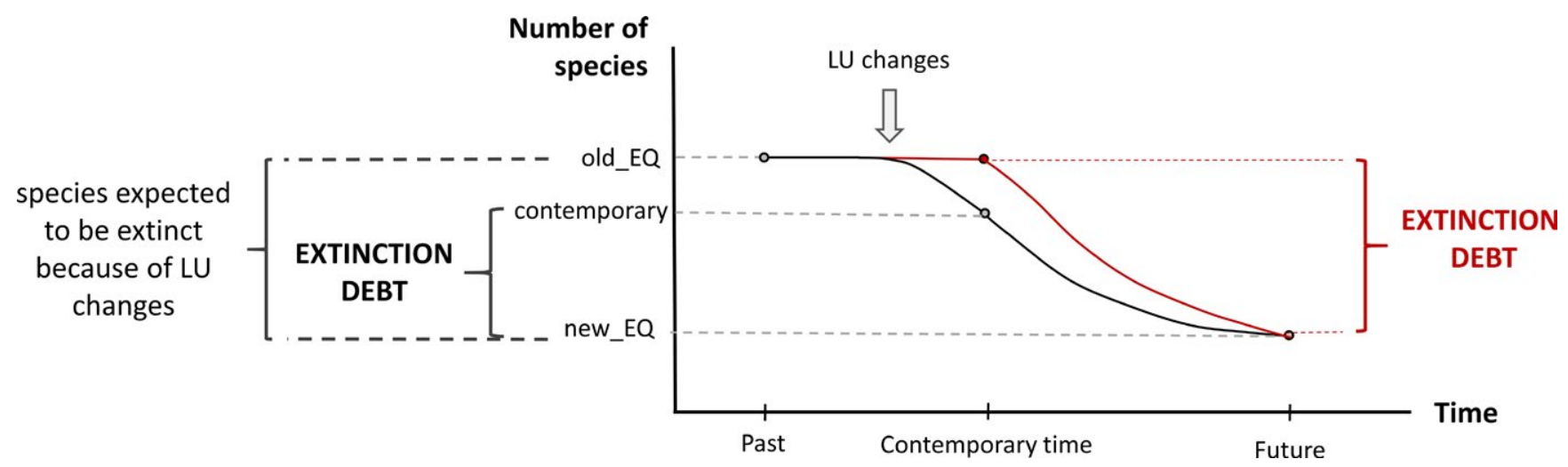

FIGURE 2 Species can be lost immediately after land-use change or with a time delay. Extinction debt refers to those species that will go extinct in the future (compared to now). Extinction debt can be lower than the total number of species lost if some species have already gone locally extinct 


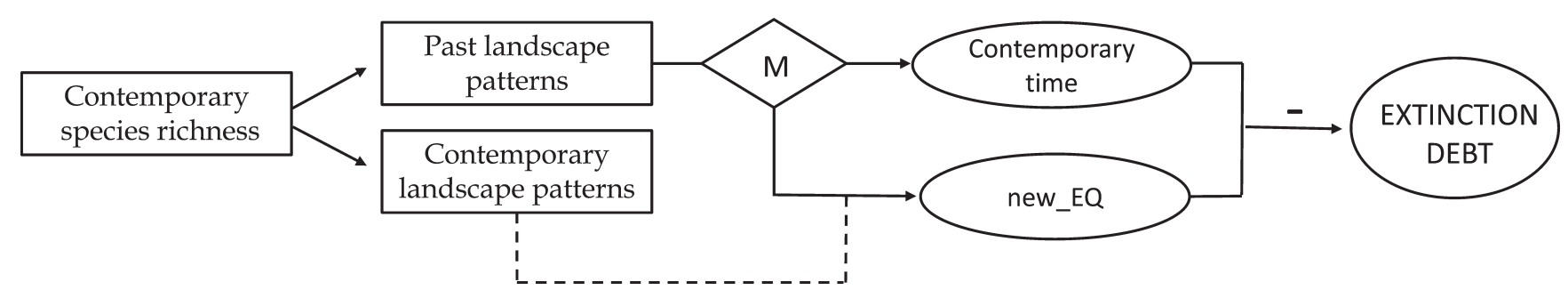

FIGURE 3 Approach followed to map extinction debt. The model including past landscape patterns (our best-fitting model, M) was used to predict contemporary species richness. The same model was then projected to contemporary landscape patterns, thus predicting species richness in the new, future equilibrium (new_EQ), once extinction debt has been fully paid (and assuming no further habitat transformation). The difference in the number of species between the contemporary time and the new equilibrium represents the extinction debt

debt. We refer to this as the future equilibrium (note that this does not include the effect of possible future habitat transformation). We then calculate extinction debt as the difference between predicted contemporary and future total richness, with positive differences indicating sites where local extinctions are likely to happen.

Since the aim of our study was to investigate extinction debt caused by habitat transformation, we used the best-fitting model using only landscape variables to map extinction debt (landscape structure variables in Tables S4 and S5). We log-transformed the variable percent of core forest for the mammal dataset to meet the assumption of linearity (we had not log-transformed predictor variables when testing for extinction debt since we wanted to keep models comparable). We developed two maps showing where extinction debt is likely to occur (one for birds and one for mammals) at 300-m resolution, which required us to summarize landscape variables around each pixel using 3-km (birds) or 2-km (mammals) buffers using a circular moving window. To facilitate map interpretation, we distinguished the following classes: high extinction debt (more than $20 \%$ of contemporary species richness expected to go extinct because of past landscape transformation) and low extinction debt (5\%-20\% expected to go extinct). In addition, we identified stable areas (expected increase or decrease less than $5 \%$ ) and colonization areas (expected increase more than 5\%).

\section{3 | RESULTS}

The contemporary total species richness of both birds and mammals in the Argentine Dry Chaco was better explained by models based on past landscape variables compared to models relying on contemporary landscape variables. Models based on landscape variables from 2000 were consistently selected as best-fitting models ( $\triangle \mathrm{AIC}<2$, Table 2 ), for both birds and mammals. Models based on landscape predictors from 1985 performed worse than models containing contemporary predictors (Table 2). Comparing models with and without landscape variables showed that including landscape variables markedly improved model fitting for the best models (Table 2). The regression coefficients of the landscape variables were generally higher than those of other variables (Table 3), with the percentage of core forest and connectivity showing the strongest effects. Bird and mammal richness was positively related to core forest, for both the models using 2000 and contemporary landscape data; however, this relationship was stronger in the 2000 model
(Table 3 and Figure 4). Together, these results suggest that contemporary species richness of the entire communities was more related to past (i.e. year 2000) than contemporary landscape patterns.

Although we generally found the same pattern when investigating forest species only (i.e. predictors from 2000 explained contemporary forest species richness better than predictors from the contemporary period and 1985, Table 2), these patterns were even stronger than when considering the entire community. The contribution of landscape variables from 2000 was especially important for explaining contemporary species richness of forest species (birds $\mathrm{AICw}=1.00$; mammals AICW $=0.96$ ).

Our projections of extinction debt showed that for both birds and mammals, areas recently deforested due to agricultural expansion were most likely to experience future local bird and mammal extinctions (e.g. the Salta-Santiago del Estero border or the ChacoSantiago del Estero border; Figure 5). In contrast, few future local extinctions were expected in areas with larger patches of forest such as Copo National Park (North of Santiago del Estero Province) or the Impenetrable (North of Chaco Province). Although the spatial patterns of extinction debt were similar across birds and mammals, the magnitude of the extinction debt was higher for birds. High extinction debt was predicted for a larger area for birds ( $5 \%$ of the study region) than for mammals ( $0.3 \%$ of the study region, Figure 5 and Figure S3). In addition, high extinction debt for birds was similar in areas converted to crops and pastures (Figure 6). Low extinction debt, both for birds and for mammals, was more likely to occur in forested areas around agricultural fields (Figures 5 and 6).

\section{DISCUSSION}

Habitat loss and fragmentation threaten biodiversity globally, and understanding time-delayed responses of communities to habitat transformation might help to counteract future extinctions. We found strong evidence for extinction debt for birds and mammals in the Argentine Dry Chaco, but also that this extinction debt may be paid soon. Interestingly, relaxation time (i.e. the time needed to reach a new, future equilibrium) was similar for birds and mammals (between 10 and 25 years), and for forest specialists and the entire community. Additionally, extinction debt is more likely to occur in areas where agriculture has expanded recently, but its magnitude is comparable 
TAB LE 2 AIC, $\triangle$ AIC and model weights (AICW) for all candidate models (ranked by AIC). Full models include all predictors, noLS models exclude landscape structure predictors and null models do not include any predictors

\begin{tabular}{|c|c|c|c|c|c|c|c|}
\hline \multicolumn{4}{|l|}{ All species } & \multicolumn{4}{|l|}{ Forest species } \\
\hline \multicolumn{8}{|l|}{ Birds } \\
\hline Birds_2000_full & $1,618.89$ & 0.00 & 0.76 & BirdsFor_2000_full & $1,248.67$ & 0.00 & 1.00 \\
\hline Birds_contemp_full & $1,621.18$ & 2.29 & 0.24 & BirdsFor_contemp_full & $1,260.31$ & 11.65 & 0.00 \\
\hline Birds_2000_noLS & $1,637.54$ & 18.65 & 0.00 & BirdsFor_2000_noLS & $1,277.32$ & 28.65 & 0.00 \\
\hline Birds_contemp_noLS & $1,654.61$ & 35.72 & 0.00 & BirdsFor_contemp_noLS & $1,313.04$ & 64.37 & 0.00 \\
\hline Birds_null & $1,684.00$ & 65.10 & 0.00 & BirdsFor_null & $1,359.73$ & 111.07 & 0.00 \\
\hline \multicolumn{8}{|l|}{ Mammals } \\
\hline Mam_1985_noLS & $1,009.12$ & 7.31 & 0.02 & Mam_contemp_noLS & 523.90 & 20.85 & 0.00 \\
\hline Mam_contemp_noLS & $1,010.20$ & 8.39 & 0.01 & Mam_1985_full & 529.75 & 26.70 & 0.00 \\
\hline Mam_null & $1,011.76$ & 9.95 & 0.01 & Mam_1985_noLS & 532.85 & 29.80 & 0.00 \\
\hline Mam_2000_noLS & $1,014.76$ & 12.95 & 0.00 & Mam_null & 546.09 & 43.05 & 0.00 \\
\hline
\end{tabular}

TAB LE 3 Parameter estimates of the two best models (contemporary and 2000 period in Table 2). For the bird models, fixed effects estimates from the linear mixed models are shown. For the mammal models, estimates are derived from linear models. All variables are standardized to 0 mean and 1 standard deviation for comparison

\begin{tabular}{|c|c|c|c|c|c|c|c|c|}
\hline & \multicolumn{4}{|l|}{ Birds } & \multicolumn{4}{|l|}{ Mammals } \\
\hline & \multicolumn{2}{|c|}{ Contemporary } & \multicolumn{2}{|l|}{2000} & \multicolumn{2}{|c|}{ Contemporary } & \multicolumn{2}{|l|}{2000} \\
\hline Intercept & 19.83 & $22.76,16.91$ & 19.03 & $22.05,16.01$ & 3.74 & $4.04,3.45$ & 3.74 & $4.04,3.45$ \\
\hline Core & 2.87 & $4.62,1.13$ & 4.46 & $6.25,2.66$ & 0.79 & $1.29,0.29$ & 0.82 & $1.23,0.41$ \\
\hline Connec & 3.30 & $4.82,1.77$ & 1.88 & $3.43,0.33$ & 0.18 & $0.56,-0.21$ & & \\
\hline DistTowns & -1.02 & $0.31,-2.34$ & -1.64 & $-0.29,-2.98$ & & & & \\
\hline DistRoads & 0.49 & $1.85,-0.87$ & 1.79 & $3.46,0.12$ & -0.06 & $0.32,-0.44$ & 0.13 & $0.52,-0.25$ \\
\hline DensRoads & -1.00 & $0.15,-2.16$ & -0.70 & $0.45,-1.85$ & 0.10 & $0.47,-0.26$ & 0.19 & $0.61,-0.22$ \\
\hline DistPuestos & -0.66 & $0.68,-2.00$ & 0.41 & $1.99,-1.16$ & & & -0.08 & $0.45,-0.6$ \\
\hline DensRivers & 0.68 & $1.97,-0.61$ & 1.21 & $2.55,-0.14$ & & & & \\
\hline DistWater & 1.47 & $2.93,0.02$ & 1.75 & $3.29,0.21$ & -0.33 & $0.03,-0.70$ & -0.24 & $0.18,-0.65$ \\
\hline
\end{tabular}

across systems with different post-deforestation land use (e.g. ranching vs. cropping). In these areas, up to $56 \%$ and $29 \%$ of the extant birds and mammals, respectively, may go locally extinct if conservation actions are not implemented soon.

Past landscape structure explained contemporary bird and mammal richness better than contemporary landscape structure, supporting the hypothesis of time-delayed responses to habitat transformation in the Chaco. This seems reasonable given the high rate of habitat transformations in deforestation frontiers (Baumann et al., 2017; Carlson et al., 2013; Numata, Cochrane, Souza, \& Sales, 2011) and is in line with the few studies that have investigated extinction debt in such highly dynamic landscapes (Lira et al., 2012; Metzger et al., 2009). Our 

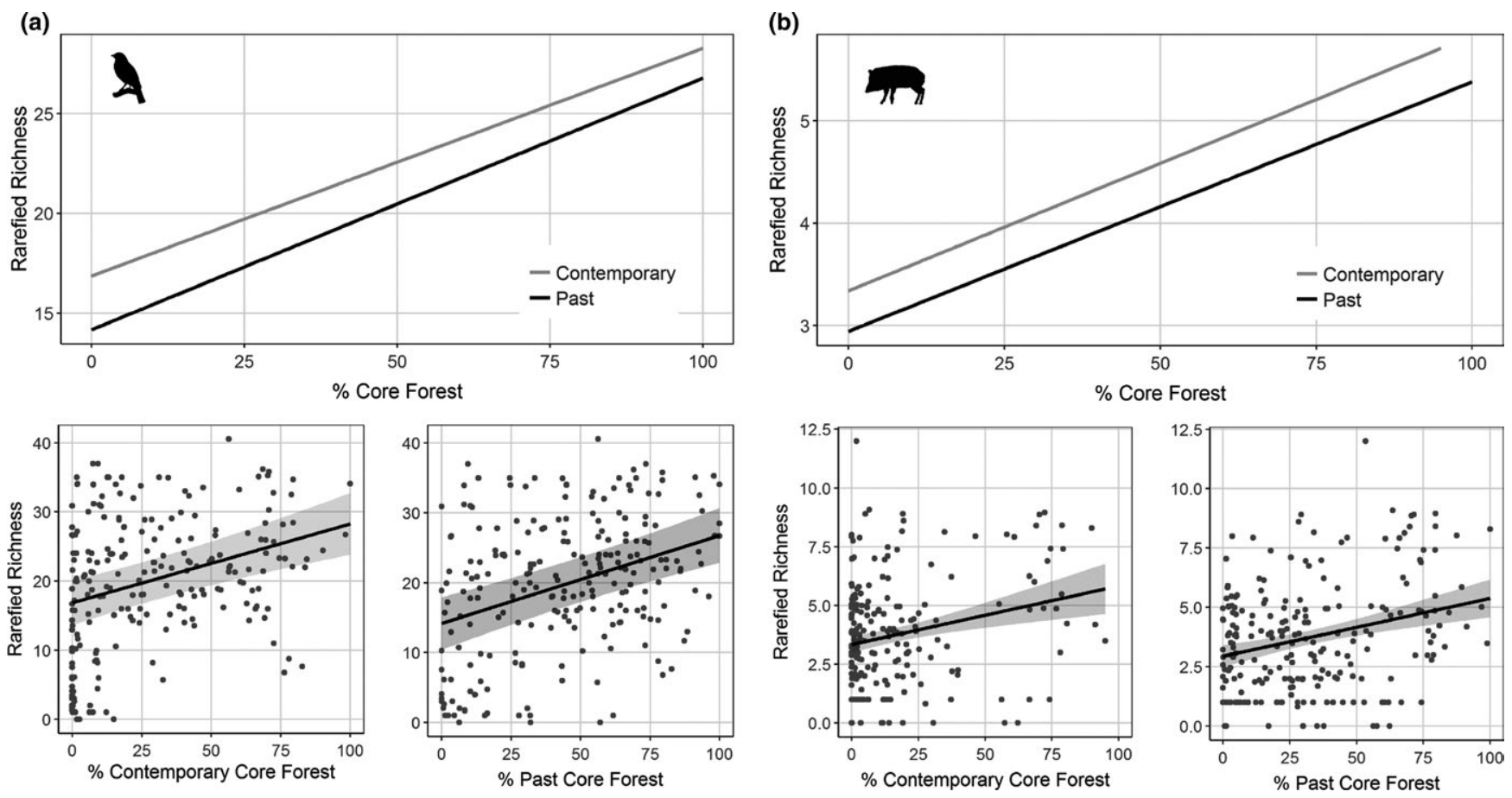

FIGURE 4 Correlation between contemporary (a) bird and (b) mammal richness and contemporary and past (2000) percentage of core forest. Upper graphs show regression lines for both contemporary and past core forest. The lower graphs show the linear regression between rarefied richness and percentage of core forest for each period separately (with 95\% confidence intervals around regression lines)

long-term forest-cover dataset allowed us to provide upper and lower bounds for this time delay: landscape patterns from 2000 explained contemporary richness best, indicating that average relaxation time is greater than 10 years, but contemporary richness was not associated with 1985-landscape structure, suggesting that relaxation time is less than 25 years. Major landscape transformation in the Chaco landscape began only at the end of the 20th century (Baumann et al., 2017; Caldas et al., 2015), explaining why bird and mammal communities were likely still in equilibrium in 1985.

The time-delayed response of c. 10-25 years we found is similar to those found in other studies for vertebrates. For example, MacHunter, Wright, Loyn, and Rayment (2006) found an evidence of relaxation time for birds of 22 years in southeastern Australia. Similarly, Sales et al. (2015) reported a time-delayed response of 11 years for a primate species in Brazil. An exception is the work by Brooks et al. (1999), who estimated relaxation times for tropical birds of $>50$ years using species-area relationships. Such models, however, are prone to overestimate extinction risk and thus extinction debt (He \& Hubbell, 2011). The relaxation time we found is considerably shorter than that found for plants (Helm et al., 2006; Krauss et al., 2010; Lindborg \& Eriksson, 2004) which can exceed a century (Vellend et al., 2006).

Extinction debt did not vary substantially among birds and mammals. Species-specific traits, such as longevity, home range size, diet or habitat association, may influence extinction debt, but the evidence remains inconclusive (Hylander \& Ehrlén, 2013; Kuussaari et al., 2009). For example, Metzger et al. (2009) found extinction debt for birds in the Atlantic Forest but not for small mammals, while another study from the same region did not find extinction debt for either taxa (Lira et al., 2012). Although there is a general lack of information on the longevity of many species we studied, a likely explanation for the similar time delays we found are relatively similar longevity and generation times (e.g. average longevity for Chacoan mammals is around 15 years (Bobick \& Peffer, 1993; Grzimek, 1990), while average longevity for Neotropical birds is around 10 years (Snow \& Lill, 1974). Further research is needed to clarify the effect of longevity or other traits on extinction debt. In addition, that both taxa had time-delayed responses to landscape transformation suggests both birds and mammals in the Chaco are equally habitat-dependent.

While we found extinction debt both for forest species and the entire community, support was stronger for forest species. This can be expected and supports the idea that assessing only specialist species may be more effective for detecting extinction debt (Kuussaari et al., 2009). On the other hand, reliably classifying species into forest and non-forest specialists is challenging in tropical dry forests and savannas that are characterized by heterogeneous landscapes and ecotones (Murphy \& Lugo, 1986). The fact that we found extinction debt for the bird and mammal communities as a whole highlights that even those species not strictly linked to forests may still critically depend on the forest (e.g. anteaters use forest patches to shelter and rest; Quiroga, Noss, Boaglio, \& Di Bitetti, 2016). By omitting these species, extinction debt may thus be underestimated.

Our maps of unpaid extinction debt in the Argentine Dry Chaco indicated similar spatial patterns for both birds and mammals, but different magnitudes. Higher extinction debt was predicted in areas where deforestation has been most drastic recently. These areas were mostly classified as having high extinction debt for birds but low extinction 

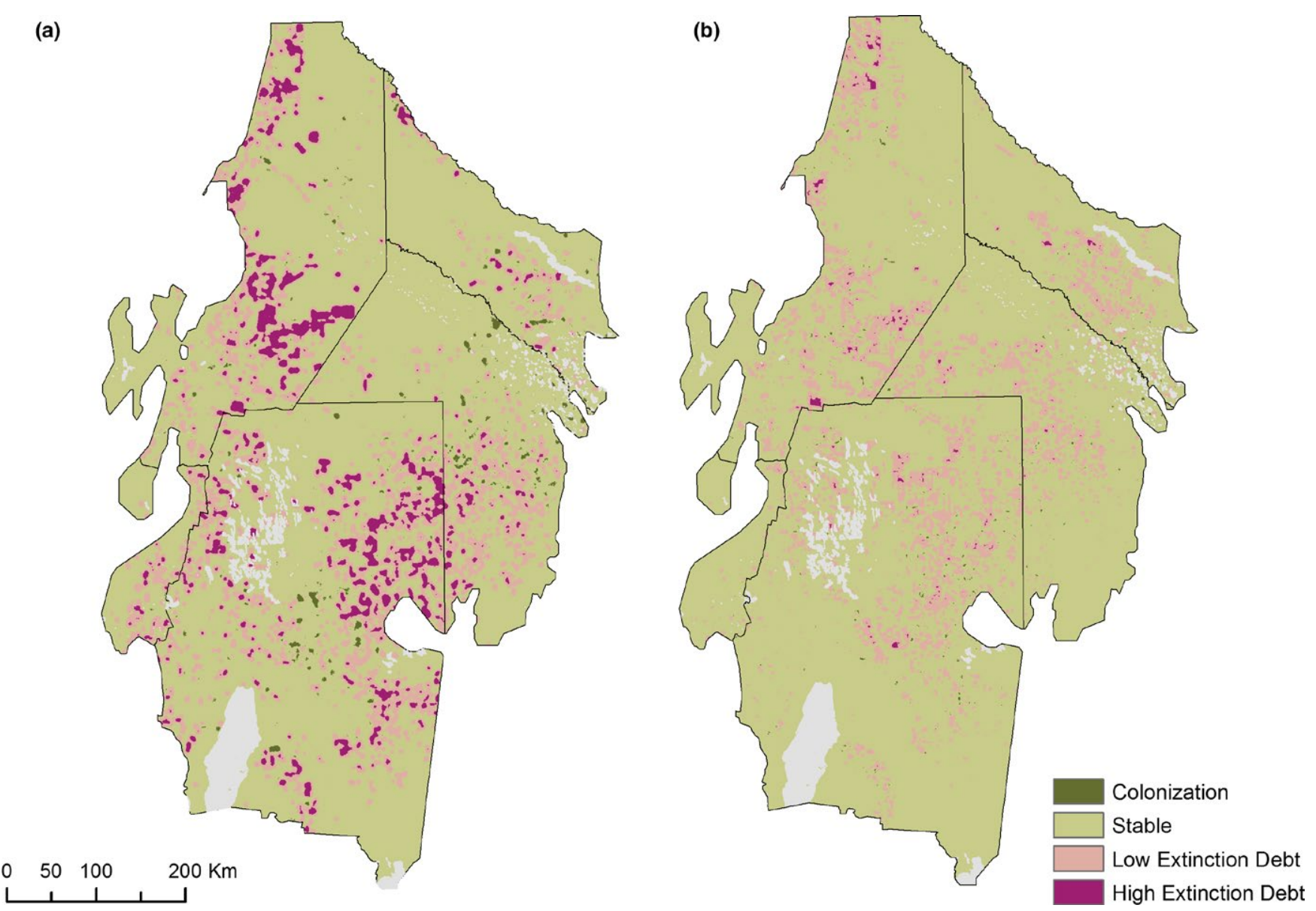

FIGURE 5 Extinction debt for (a) birds and (b) mammals in the study region. Permanent water bodies and salt plains are depicted as light grey. Four categories are represented in the map: high extinction debt (future decrease $>20 \%$ compared to contemporary richness), low extinction debt (future decrease $5 \%-20 \%)$, stable areas ( $<5 \%$ increase or decrease) and colonization areas $(>5 \%)$

(a)

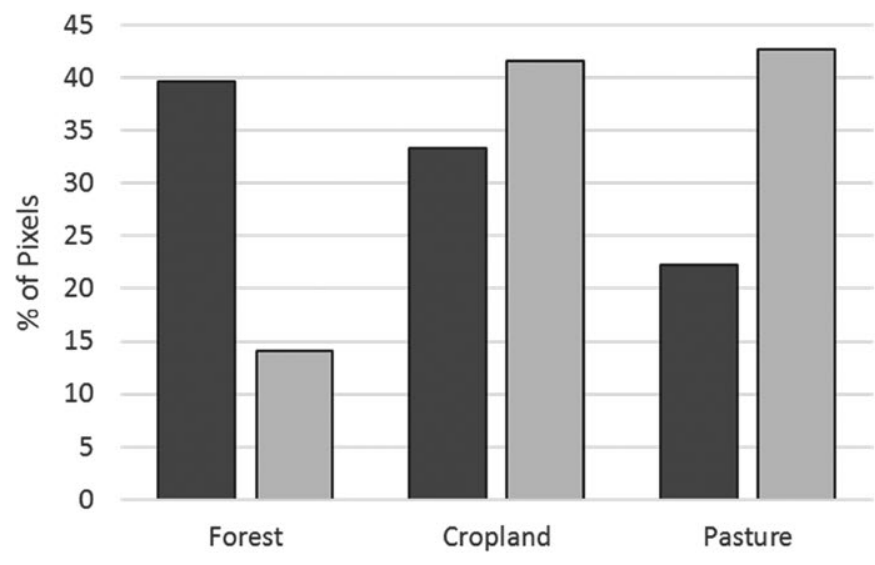

Low Extinction Debt (b)

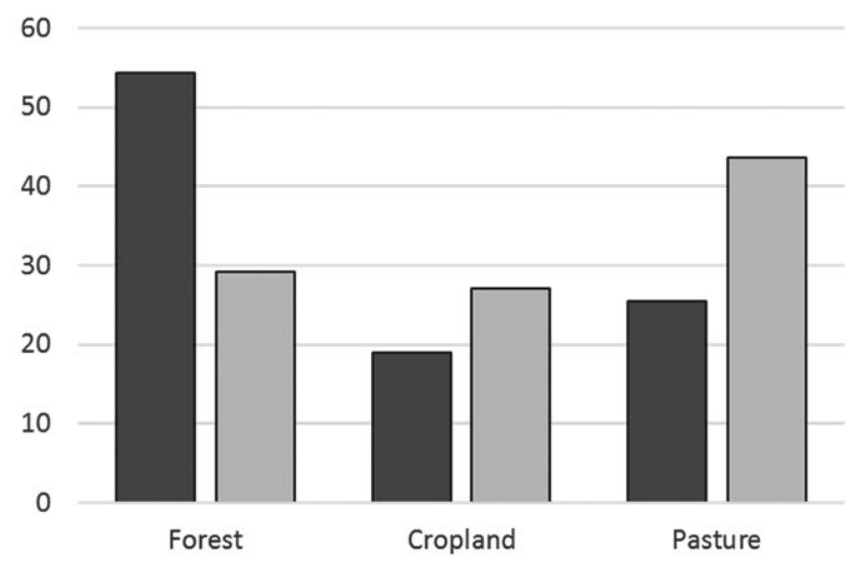

High Extinction Debt

FIGURE 6 Percentage of extinction debt pixels located in forest, cropland and pasture pixels for (a) birds and (b) mammals. The graph is the result of the intersection between our extinction debt map and the 2013 land-cover map from Baumann et al. (2017)

debt for mammals, suggesting that although both taxa were affected by extinction debt, that is, a percent of the contemporary number of species will go extinct due to past landscape transformation, this percentage is higher for birds than for mammals. These results are similar to the findings of Wearn et al. (2012) who also reported higher magnitudes of extinction debt for birds than for mammals. Extinction 
debt was small in areas still characterized by high forest cover, such as the Copo NP and the Impenetrable NP, or areas unsuitable for intensified agriculture, such as the regularly flooded areas in the north of our study region.

Interestingly, extinction debt for birds did not differ much between post-deforestation land uses (cropland or pastures). This can be explained by the conversion process itself, which is equally drastic for both post-deforestation land uses, since all natural vegetation is removed and exotic grasses are sown when converting to intensified pastures (Baumann et al., 2017). Low extinction debt for both birds and mammals, instead, was generally found in forested areas located around crops and pastures, highlighting the importance of the landscape context.

We used an extensive field dataset to quantify and map extinction debt in the Dry Chaco, and our models were very robust. Still, our analyses do not come without uncertainty. First, while we used a large field dataset, additional data covering a larger area would have been useful, especially for mammals. Second, while we have explored extinction debt for both, forest and the entire community, our models for forest species did not allow projecting extinction debt in space. Few approaches exist for zero-inflated datasets (Zuur \& leno, 2016), and our hurdle modelling approach does not allow for predicting in space. Developing statistical methods to better deal with zero-inflated datasets would be useful to overcome such limitations. Third, we conservatively rarified our bird data to the lowest number of point counts (4), which may underestimate extinction debt. Rerunning all our analyses for rarefication to 6 and 9 point counts did not change any of our conclusions (Figure S4), but our maps of extinction debt are likely conservative. Finally, we considered land conversions only, whereas forest degradation is also widespread and may play an important role in relation to extinction debt. Including forest degradation, as soon as adequate data become available, as an explanatory variable in models estimating extinction debt will therefore represent an important advancement.

\section{1 | Synthesis and applications}

Several major implications for conservation planning derive from our work. First, our results show that bird and mammal richness in active deforestation frontiers does respond to habitat loss with a time delay and therefore, predicting species richness without considering extinction debt may lead to an overestimation of the contemporary number of species (Figures S5 and S6). This is encouraging as our results also suggest that despite drastic habitat loss, a window of opportunity may often exist for saving species otherwise likely facing extinction. In such cases, conservation planning should not only focus on protecting remaining forests, but also exploring options to restore already transformed areas. However, our results highlight that extinction debt for birds and mammals in the Chaco, some of which are of conservation concern, may be paid relatively quickly. In our case, the time to a new equilibrium state, when extinction debt will have been paid, may be as short as a decade, highlighting the urgency of conservation action if local extinctions are to be averted. Second, extinction debt was highest in areas where agricultural activities are expanding, with small differences regarding post-deforestation land use for birds. This provides a cautionary note regarding the compatibility of cattle ranching with biodiversity conservation, at least in terms of the intensified ranching systems that have expanded in the Chaco since 2000. Finally, many of the world's active agricultural frontiers are located in tropical forests and savannas that harbour high biodiversity (Schiesari, Waichman, Brock, Adams, \& Grillitsch, 2013). Our study shows that considering land-use legacies and time-delayed responses of biodiversity to habitat transformations, especially in highly dynamic landscapes, is critical for effective biodiversity monitoring and conservation planning.

\section{ACKNOWLEDGEMENTS}

We thank H. Ricardo Grau, N. Ignacio Gasparri, T. Mitchell Aide, the Argentine National Institute of Agrarian Technologies (INTA) and the Consejo Nacional de Investigaciones Científicas y Técnicas (CONICET) for sharing data. We are grateful to C. Levers and G.I. Gavier-Pizarro for helpful discussions. We also thank E.A. Law for language check. We gratefully acknowledge funding by the German Ministry of Education and Research (BMBF, project PASANOA, 031B0034A) and the German Research Foundation (DFG, project KU 2458/5-1). We are grateful to two anonymous reviewers and Dr. Banks-Leite for extremely thoughtful and constructive comments on prior manuscript versions.

\section{AUTHORS' CONTRIBUTIONS}

A.S.P. and T.K. conceived the ideas and designed methodology; L.M., J.D., P.G.B., B.G.V., M.B. and M.M. generated the input data; A.S.P. and F.M.S. analysed the data; A.S.P. led the writing. All authors contributed critically to the drafts and gave final approval for publication.

\section{DATA ACCESSIBILITY}

Data available from the Dryad Digital Repository https://doi. org/10.5061/dryad.d362v (Semper-Pascual et al., 2017).

\section{ORCID}

Asunción Semper-Pascual iD http://orcid.org/0000-0001-7376-9214

\section{REFERENCES}

Bates, D., Maechler, M., Bolker, B., \& Walker, S. (2015). Fitting linear mixedeffects models using Ime4. Journal of Statistical Software, 67, 1-48.

Baumann, M., Gasparri, I., Piquer-Rodríguez, M., Gavier Pizarro, G., Griffiths, P., Hostert, P., \& Kuemmerle, T. (2017). Carbon emissions from agricultural expansion and intensification in the Chaco. Global Change Biology, 23, 1902-1916. https://doi.org/10.1111/gcb.13521

Beisiegel, B., \& Mantovani, W. (2006). Habitat use, home range and foraging preferences of the coati Nasua nasua in a pluvial tropical Atlantic forest area. Journal of Zoology, 269, 77-87. https://doi. org/10.1111/j.1469-7998.2006.00083.x 
Bobick, J. E., \& Peffer, M. (1993). Science and technology desk reference. Washington, DC: Gale Research Inc.

Brooks, T. M., Pimm, S. L., \& Oyugi, J. O. (1999). Time lag between deforestation and bird extinction in tropical forest fragments. Conservation Biology, 13, 1140-1150. https://doi.org/10.1046/j.1523-1739.1999.98341.x

Bucher, E. H., \& Huszar, P. C. (1999). Sustainable management of the Gran Chaco of South America: Ecological promise and economic constraints. Journal of Environmental Management, 57, 99-108. https://doi. org/10.1006/jema.1999.0290

Burnham, K. P., \& Anderson, D. R. (2002). Model selection and multi-model inference: A practical information-theoretic approach. New York, NY: Springer.

Cabrera, A., \& Willink, A. (1973). Biogeografía de América Latina. Programa Regional de Desarrollo Científico y Tecnológico, Serie Biología. Monografía.

Caldas, M. M., Goodin, D., Sherwood, S., Campos Krauer, J. M., \& Wisely, S. M. (2015). Land-cover change in the Paraguayan Chaco: 2000-2011. Journal of Land Use Science, 10, 1-18. https://doi.org/10.1080/17474 23X.2013.807314

Canevari, M., \& Vaccaro, O. (2007). Guía de mamíferos del sur de América del Sur. Buenos Aires: LOLA.

Carlson, K. M., Curran, L. M., Asner, G. P., Pittman, A. M., Trigg, S. N., \& Adeney, J. M. (2013). Carbon emissions from forest conversion by Kalimantan oil palm plantations. Nature Climate Change, 3, 283-287.

Ceballos, G., Ehrlich, P. R., Barnosky, A. D., García, A., Pringle, R. M., \& Palmer, T. M. (2015). Accelerated modern human-induced species losses: Entering the sixth mass extinction. Science Advances, 1, e1400253. https://doi.org/10.1126/sciadv.1400253

Chen, Y., \& Peng, S. (2017). Evidence and mapping of extinction debts for global forest-dwelling reptiles, amphibians and mammals. Scientific Reports, 7, 44305. https://doi.org/10.1038/srep44305

Colwell, R. K., Chao, A., Gotelli, N. J., Lin, S.-Y., Mao, C. X., Chazdon, R. L., \& Longino, J. T. (2012). Models and estimators linking individual-based and sample-based rarefaction, extrapolation and comparison of assemblages. Journal of Plant Ecology, 5, 3-21. https://doi.org/10.1093/jpe/ rtr044

Cowlishaw, G. (1999). Predicting the pattern of decline of African primate diversity: An extinction debt from historical deforestation. Conservation Biology, 13, 1183-1193. https://doi.org/10.1046/j.1523-1739.1999.98433.x

Decarre, J. (2015). Diversity and structure of bird and mammal communities in the Semiarid Chaco Region: response to agricultural practices and landscape alterations. Unpublished doctoral thesis, Imperial College London, London, UK.

Deconchat, M., Brockerhoff, E., \& Barbaro, L. (2009). Effects of surrounding landscape composition on the conservation value of native and exotic habitats for native forest birds. Forest Ecology and Management, 258, S196-S204. https://doi.org/10.1016/j.foreco.2009.08.003

Ehrlich, P. R., \& Pringle, R. M. (2008). Where does biodiversity go from here? A grim business-as-usual forecast and a hopeful portfolio of partial solutions. Proceedings of the National Academy of Sciences of the United States of America, 105, 11579-11586. https://doi.org/10.1073/ pnas.0801911105

Essl, F., Dullinger, S., Rabitsch, W., Hulme, P. E., Pyšek, P., Wilson, J. R., \& Richardson, D. M. (2015). Delayed biodiversity change: No time to waste. Trends in Ecology \& Evolution, 30, 375-378. https://doi. org/10.1016/j.tree.2015.05.002

Foley, J. A., DeFries, R., Asner, G. P., Barford, C., Bonan, G., Carpenter, S. R., ... Gibbs, H. K. (2005). Global consequences of land use. Science, 309, 570-574. https://doi.org/10.1126/science.1111772

Gasparri, N. I., \& Baldi, G. (2013). Regional patterns and controls of biomass in semiarid woodlands: Lessons from the Northern Argentina Dry Chaco. Regional Environmental Change, 13, 1131-1144. https://doi. org/10.1007/s10113-013-0422-x

Gómez-Valencia, B. (2017). Medianos y grandes mamíferos en fragmentos de bosque de tres quebrachos, sudoeste de la provincia del Chaco. Tesis de Doctorado, Universidad De Buenos Aires.
Grau, H. R., Gasparri, N. I., \& Aide, T. M. (2005). Agriculture expansion and deforestation in seasonally dry forests of north-west Argentina. Environmental Conservation, 32, 140-148. https://doi.org/10.1017/ S0376892905002092

Grzimek, B. (1990). Grzimek's encyclopedia of mammals. New York, NY: McGraw-Hill.

Hansen, M. C., Potapov, P. V., Moore, R., Hancher, M., Turubanova, S., Tyukavina, A., ... Loveland, T. (2013). High-resolution global maps of 21st-century forest cover change. Science, 342, 850-853. https://doi. org/10.1126/science.1244693

Hanski, I., \& Ovaskainen, O. (2002). Extinction debt at extinction threshold. Conservation Biology, 16, 666-673. https://doi. org/10.1046/j.1523-1739.2002.00342.x

He, F., \& Hubbell, S. P. (2011). Species-area relationships always overestimate extinction rates from habitat loss. Nature, 473, 368-371. https:// doi.org/10.1038/nature09985

Helm, A., Hanski, I., \& Pärtel, M. (2006). Slow response of plant species richness to habitat loss and fragmentation. Ecology Letters, 9 , 72-77.

Herrault, P.-A., Larrieu, L., Cordier, S., Gimmi, U., Lachat, T., Ouin, A., ... Sheeren, D. (2016). Combined effects of area, connectivity, history and structural heterogeneity of woodlands on the species richness of hoverflies (Diptera: Syrphidae). Landscape Ecology, 31, 877-893. https:// doi.org/10.1007/s10980-015-0304-3

del Hoyo, J. (2015). Handbook of the birds of the world alive. Barcelona, Spain: Lynx Edicions.

Hsieh, T. C., Ma, K. H., \& Chao, A. (2016). iNEXT: iNterpolation and EXTrapolation for species diversity. R package version 2.0.12.

Hylander, K., \& Ehrlén, J. (2013). The mechanisms causing extinction debts. Trends in Ecology \& Evolution, 28, 341-346. https://doi.org/10.1016/ j.tree.2013.01.010

IUCN. (2016). The IUCN Red List of Threatened Species. Version 2016-3.

Kasper, C. B., Soares, J. B., \& Freitas, T. R. (2012). Differential patterns of home-range, net displacement and resting sites use of Conepatus chinga in southern Brazil. Mammalian Biology-Zeitschrift für Säugetierkunde, 77, 358-362. https://doi.org/10.1016/j.mambio.2012.03.006

Krauss, J., Bommarco, R., Guardiola, M., Heikkinen, R. K., Helm, A., Kuussaari, M., ... Pino, J. (2010). Habitat fragmentation causes immediate and time-delayed biodiversity loss at different trophic levels. Ecology Letters, 13, 597-605. https://doi.org/10.1111/j.1461-0248.2010.01457.x

Kuemmerle, T., Altrichter, M., Baldi, G., Cabido, M., Camino, M., Cuellar, E., ... Zak, M. (2017). Forest conservation: Remember Gran Chaco. Science, 355, 465-465.

Kuussaari, M., Bommarco, R., Heikkinen, R. K., Helm, A., Krauss, J., Lindborg, R., ... Roda, F. (2009). Extinction debt: A challenge for biodiversity conservation. Trends in Ecology \& Evolution, 24, 564-571. https://doi. org/10.1016/j.tree.2009.04.011

Lindborg, R., \& Eriksson, O. (2004). Historical landscape connectivity affects present plant species diversity. Ecology, 85, 1840-1845. https:// doi.org/10.1890/04-0367

Lira, P. K., Ewers, R. M., Banks-Leite, C., Pardini, R., \& Metzger, J. P. (2012). Evaluating the legacy of landscape history: Extinction debt and species credit in bird and small mammal assemblages in the Brazilian Atlantic Forest. Journal of Applied Ecology, 49, 1325-1333. https://doi. org/10.1111/j.1365-2664.2012.02214.x

Macchi, L., Grau, H. R., Zelaya, P. V., \& Marinaro, S. (2013). Trade-offs between land use intensity and avian biodiversity in the dry Chaco of Argentina: A tale of two gradients. Agriculture, Ecosystems \& Environment, 174, 11-20. https://doi.org/10.1016/j.agee.2013.04.011

MacHunter, J., Wright, W., Loyn, R., \& Rayment, P. (2006). Bird declines over 22 years in forest remnants in southeastern Australia: Evidence of faunal relaxation? Canadian Journal of Forest Research, 36, 2756-2768. https://doi.org/10.1139/x06-159

Mastrangelo, M. E., \& Gavin, M. C. (2012). Trade-offs between cattle production and bird conservation in an agricultural frontier of the Gran 
Chaco of Argentina. Conservation Biology, 26, 1040-1051. https://doi. org/10.1111/j.1523-1739.2012.01904.x

Mastrangelo, M. E., \& Gavin, M. C. (2014). Impacts of agricultural intensification on avian richness at multiple scales in Dry Chaco forests. Biological Conservation, 179, 63-71. https://doi.org/10.1016/ j.biocon.2014.08.020

May, R. M., \& Lawton, J. H. (1995). Extinction rates. Oxford: Oxford University Press.

McGarigal, K. (2014). FRAGSTATS help. Amherst, MA: University of Massachusetts.

Metzger, J. P., Martensen, A. C., Dixo, M., Bernacci, L. C., Ribeiro, M. C., Teixeira, A. M. G., \& Pardini, R. (2009). Time-lag in biological responses to landscape changes in a highly dynamic Atlantic forest region. Biological Conservation, 142, 1166-1177. https://doi.org/10.1016/ j.biocon.2009.01.033

Mitchell, M. S., Lancia, R. A., \& Gerwin, J. A. (2001). Using landscape-level data to predict the distribution of birds on a managed forest: Effects of scale. Ecological Applications, 11, 1692-1708. https://doi.org/10.1890/ 1051-0761(2001)011[1692:ULLDTP]2.0.CO;2

Murphy, P. G., \& Lugo, A. E. (1986). Ecology of tropical dry forest. Annual Review of Ecology and Systematics, 17, 67-88. https://doi.org/10.1146/ annurev.es.17.110186.000435

Nori, J., Torres, R., Lescano, J. N., Cordier, J. M., Periago, M. E., \& Baldo, D. (2016). Protected areas and spatial conservation priorities for endemic vertebrates of the Gran Chaco, one of the most threatened ecoregions of the world. Diversity and Distributions, 22, 1212-1219. https://doi. org/10.1111/ddi.12497

Numata, I., Cochrane, M. A., Souza, C. M. Jr, \& Sales, M. H. (2011). Carbon emissions from deforestation and forest fragmentation in the Brazilian Amazon. Environmental Research Letters, 6, 044003 . https://doi. org/10.1088/1748-9326/6/4/044003

Oksanen, J., Blanchet, F. G., Friendly, M., Kindt, R., Legendre, P., McGlinn, D., ... Wagner, H. (2016). Vegan: Community Ecology Package. R package version 2.4-1.

Ovaskainen, O., \& Hanski, I. (2002). Transient dynamics in metapopulation response to perturbation. Theoretical Population Biology, 61, 285-295. https://doi.org/10.1006/tpbi.2002.1586

Pimm, S. L., Jenkins, C. N., Abell, R., Brooks, T. M., Gittleman, J. L., Joppa, L. N., ... Sexton, J. O. (2014). The biodiversity of species and their rates of extinction, distribution, and protection. Science, 344, 1246752. https:// doi.org/10.1126/science.1246752

Pinheiro, J., Bates, D., DebRoy, S., \& Sarkar, D.; R Core Team. (2016). nlme: Linear and nonlinear mixed effects models. R package version 3.1-128.

Quiroga, V. A., Noss, A. J., Boaglio, G. I., \& Di Bitetti, M. S. (2016). Local and continental determinants of giant anteater (Myrmecophaga tridactyla) abundance: Biome, human and jaguar roles in population regulation. Mammalian Biology-Zeitschrift für Säugetierkunde, 81, 274-280. https:// doi.org/10.1016/j.mambio.2016.03.002

Ridgely, R. S., \& Tudor, G. (1994). The birds of South America. Vol. 2, The suboscine passerines: Ovenbirds and woodcreepers, typical and ground antbirds, gnateaters and tapaculos, tyrant flycatchers, cotingas and manakins. Oxford: Oxford University Press.

Sales, L. P., Hayward, M. W., Zambaldi, L., Passamani, M., de Melo, F. R., \& Loyola, R. (2015). Time-lags in primate occupancy: A study case using dynamic models. Natureza \& Conservação, 13, 139-144. https://doi. org/10.1016/j.ncon.2015.10.003

Schai-Braun, S. C., \& Hackländer, K. (2014). Home range use by the European hare (Lepus europaeus) in a structurally diverse agricultural landscape analysed at a fine temporal scale. Acta Theriologica, 59, 277287. https://doi.org/10.1007/s13364-013-0162-9

Schielzeth, H. (2010). Simple means to improve the interpretability of regression coefficients. Methods in Ecology and Evolution, 1, 103-113. https://doi.org/10.1111/j.2041-210X.2010.00012.x

Schiesari, L., Waichman, A., Brock, T., Adams, C., \& Grillitsch, B. (2013). Pesticide use and biodiversity conservation in the Amazonian agricultural frontier. Philosophical Transactions of the Royal Society of London. Series B, Biological Sciences, 368, 20120378. https://doi. org/10.1098/rstb.2012.0378

Semper-Pascual, A., Macchi, L., Sabatini, F. M., Decarre, J., Baumann, M., Blendinger, P. G., ... Kuemmerle, T. (2017). Data from: Mapping extinction debt highlights conservation opportunities for birds and mammals in the South American Chaco. Dryad Digital Repository, https://doi. org/10.5061/dryad.d362v

Short, L. L. (1975). A zoogeographic analysis of the South American chaco avifauna. Bulletin of the AMNH; v. 154, article 3.

Snow, D., \& Lill, A. (1974). Longevity records for some neotropical land birds. The Condor, 76, 262-267. https://doi.org/10.2307/1366339

Soga, M., \& Koike, S. (2013). Mapping the potential extinction debt of butterflies in a modern city: Implications for conservation priorities in urban landscapes. Animal Conservation, 16, 1-11. https://doi. org/10.1111/j.1469-1795.2012.00572.x

The Nature Conservancy (TNC), Fundación Vida Silvestre Argentina (FVSA), Fundación para el Desarrollo Sustentable del Chaco (DeSdel Chaco) \& Wildife Conservation Society Bolivia (WCS) (2005). Evaluación Ecorregional del Gran Chaco Americano/Gran Chaco Americano Ecoregional Assessment. Buenos Aires: Fundación Vida Silvestre Argentina.

Tilman, D., May, R. M., Lehman, C. L., \& Nowak, M. A. (1994). Habitat destruction and the extinction debt. Nature, 371, 65-66. https://doi. org/10.1038/371065a0

Torres, R., Gasparri, N. I., Blendinger, P. G., \& Grau, H. R. (2014). Land-use and land-cover effects on regional biodiversity distribution in a subtropical dry forest: A hierarchical integrative multi-taxa study. Regiona Environmental Change, 14, 1549-1561. https://doi.org/10.1007/ s10113-014-0604-1

VanDerWal, J., Falconi, L., Januchowski, S., Shoo, L., \& Storlie, C. (2014). SDMTools: Species Distribution Modelling Tools: Tools for processing data associated with species distribution modelling exercises. $\mathrm{R}$ package version 1.1-221.

Vellend, M., Verheyen, K., Jacquemyn, H., Kolb, A., Van Calster, H., Peterken, G., \& Hermy, M. (2006). Extinction debt of forest plants persists for more than a century following habitat fragmentation. Ecology, 87, 542548. https://doi.org/10.1890/05-1182

Vogt, P., Riitters, K. H., Estreguil, C., Kozak, J., Wade, T. G., \& Wickham, J. D. (2007). Mapping spatial patterns with morphological image processing. Landscape Ecology, 22, 171-177. https://doi.org/10.1007/ s10980-006-9013-2

Wagenmakers, E.-J., \& Farrell, S. (2004). AIC model selection using Akaike weights. Psychonomic Bulletin \& Review, 11, 192-196. https://doi. org/10.3758/BF03206482

Wearn, O. R., Reuman, D. C., \& Ewers, R. M. (2012). Extinction debt and windows of conservation opportunity in the Brazilian Amazon. Science, 337, 228-232. https://doi.org/10.1126/science.1219013

Zuur, A. F., \& leno, E. N. (2016). Beginner's guide to zero-inflated models with R. Newburgh, UK: Highland Statistics.

\section{SUPPORTING INFORMATION}

Additional Supporting Information may be found online in the supporting information tab for this article.

How to cite this article: Semper-Pascual A, Macchi L, Sabatini FM, et al. Mapping extinction debt highlights conservation opportunities for birds and mammals in the South American Chaco. J Appl Ecol. 2018;00:1-12. https://doi. org/10.1111/1365-2664.13074 